\title{
Educational attainment of Eastern European pupils in primary schools in England: Implications for policy and practice
}

\author{
Feyisa Demie* - Durham University, UK
}

\begin{abstract}
The aim of this article is to explore the attainment of Eastern European children in primary schools in England. The research draws on detailed National Pupil Database and school census data for 586,181 pupils who completed Key Stage 2 in England in 2016. Two methodological approaches were used to analyse the data. First, the performance of all pupils was analysed by ethnic and language background to illustrate patterns of attainment for each group. Second, attainment data were further analysed by social background factors to explore the main factors influencing performance in schools and the reasons for underachievement. The main findings from the study confirm that a number of Eastern European pupils have low attainment, and their performance in English schools has been masked by government statistics that fail to distinguish between 'White Other' ethnic groups. The empirical data suggest that speakers of Czech, Slovak, Hungarian, Polish, Romanian, Latvian, Lithuanian and Bulgarian are particularly underachieving, and that the difference between their educational performance and others is larger than for any other main groups. There is also a wide variation in performance between regions in England, with large attainment gaps between Eastern European and White British children. Some of the main reasons for underachievement identified from the study are the lack of fluency in English, economic deprivation, a disrupted or non-existent prior education and parental lack of understanding of the British education system. Overall, this research confirms that the underachievement of Eastern European children remains a cause for concern and is obviously an issue that policymakers and schools need to address. Implications for policy and practice are discussed in the final section.
\end{abstract}

Keywords: Eastern European; achievement; migration; language diversity and ethnic background

\section{Introduction}

\section{What does previous research tell us?}

English schools have been educating immigrant children for decades. Recently, however, new arrivals have brought challenges to schools as the majority are relatively new to English. There has been a sizable growth of immigrant population in the UK. Research conducted by the Migration Policy Institute suggests that the immigrant population as a whole increased by 76 per cent, from 4.9 million to 8.6 million between 2002 and 2015. Of these, 3.1 million were European citizens who migrated to the UK as part of the right to free movement of people and labour within the European Union (Dustmann et al., 2010; Eurostat, 2015). Of these, around 1.3 million were Eastern 
European, including 813,700 Polish and 170,000 Lithuanians (ONS, 2017). Similarly, there was an increase in school population. Of 6,626,690 pupils in English schools, about 119,580 pupils, or 1.8 per cent, are from Eastern European countries, with Polish speakers making up nearly half of this group overall with 53,915 pupils (DfE, 2016a).

However, immigration from Eastern Europe has been a 'hot topic' in the UK, with some media arguing that British schools are 'overwhelmed' by the influx of children who do not speak English as their first language. Tereshchenko and Archer (2014: 10) identify 'heightened public concern with numbers of migrant children', citing headlines such as these from the Daily Mail:

Schools are stretched to breaking point by immigrant children. (Slack, 2007)

English is now second language in one in nine schools after influx of Eastern Europeans. (Levy, 2014)

The relative underachievement of ethnic minority pupils has also been a major issue in national policy formulation, and this has generated much attention and debate since the 1980s in Britain. There have been a number of research studies into ethnic background and achievement in English schools (Demie, 2015; Strand et al., 2015). The overall findings suggest that, at the start of school, pupils from most ethnic groups substantially lag behind White British pupils and that the gaps decline for all groups through compulsory schooling. Recent data show that English schools have a higher proportion of White British, Indian, Chinese, Bangladeshi, Pakistani, Black African, Black Caribbean, White Other and mixed-race pupils compared to several other European countries. There are much lower proportions of other ethnic minority groups. The main findings of the relationship between ethnic background and attainment confirmed that there were substantial differences in performance between different ethnic groups at the end of Key Stage 2 (KS2). Of the main ethnic groups, Chinese and Indian pupils performed better compared to the national average, followed by Bangladeshi and White British. There were also several groups, such as Black Caribbean, Black Other, White Other, Mixed White and Pakistani, who were achieving below the national average at KS2 and GCSE (DfE, 2016a; Demie, 2015; Strand et al., 2015).

Previous studies (Demie, 2015; Hollingsworth and Mansaray, 2012) argue that solely using the ethnicity categories in the school census does not help further the understanding of the performance of, in particular, Eastern European and Black African pupils in English schools. A further analysis of the ethnicity data by languages spoken at home shows that, of the Black African language groups, Portuguese, Wolof, Lingala, Hausa and Bemba, Chichewa, Tigrinya and Zulu speakers were the lowest-achieving groups, while the Igbo, Edo/Bini, Yoruba, Swedish, Amharic, English, Luganda, TwiFante and Arabic speakers achieved better than the White British and the national average. The data also show that Somali, Ga, Krio, Shona and Swahili speakers are narrowing the achievement gap. Within the Indian English as an additional language (EAL) groups, the highest-performing language groups were made up of Marathi-, Telugu-, Bengali-, Malayalam- and English-speaking pupils, all performing above the national average and White British. The pupils within Pakistani language groups performed less well, with Panjabi (Pothwari), Pahari, Panjabi (other) and Kashmiri performing ten percentage points or more below the national average. Hindko-, Bengali-, English- and Gujarati-speaking Pakistani pupils all performed above the White British and the national average (Demie, 2015, 2018a).

However, within the White Other category, there is a large variation in performance depending on the language that is spoken. Previous research on the 
education background on immigrants belonging to the White Other ethnic group from the European Economic Area (EEA) suggests that, on average, they were younger and better educated than native population migrants, and that 47 per cent of them achieved tertiary education (Eurostat, 2015). Recently, however, new arrivals have brought additional challenges to schools, as the majority are relatively new to English. What is even more worrying for policy formulation is that there are no reliable statistics on the Eastern European population as a separate ethnic group in Britain. There is little clarity on the number of European Union pupils in schools. As a result of lack of data, the educational underachievement of Eastern European migrant students in British schools has seldom been mentioned in the standards debate in the last decade. Previous research noted that Eastern European pupils were classified confusingly under the White Other ethnic group in the schools census (Demie, 2015; Tereshchenko and Archer, 2014; Hollingsworth and Mansaray, 2012). There is therefore a need to unpick how national categories may be used to improve our understanding of the performance of pupils who speak different Eastern European languages in schools. The few recent studies of attainment and language spoken at home for Eastern European pupils suggest that there are significant differences between ethnic categories and language spoken. For example, KS2 and GCSE data analysis of White Other ethnic group achievement by languages in one inner London local authority suggests that, within the White Other ethnic category, there is a large variation in performance depending on the language that is spoken (Demie, 2015). The highest-achieving groups at KS2 and GCSE were West European language speakers of German, Dutch, French and Swedish, who all outperformed pupils who had English as a first language. The lowestachieving groups were from Eastern Europe, including pupils speaking Russian, Polish, Albanian, Czech, Slovak and Romany, with very few in these groups achieving expected outcomes. Also low performing were Romanian-, Latvian-, Hungarian- and Lithuanianspeaking pupils, with barely half of these pupils achieving expected levels. Of the larger European language groups in English schools, Polish, Portuguese, Turkish and Kurdish speakers were achieving below the national average (Demie, 2018a; Tereshchenko and Archer, 2014; Strand et al., 2015; Hollingsworth and Mansaray, 2012). Similar findings also emerged from other studies using National Pupil Database (NPD) attainment and language data, confirming that pupils of Eastern European origins, as a group, performed below the national average (see Tereshchenko and Archer, 2014; Demie, 2018a). These studies show that achievement of Eastern European heritage pupils lags far behind the average achievement of the majority of their peers, and that the gap is growing at the end of primary and the end of secondary education.

Previous studies attribute the roots of underachievement to a number of factors, including lack of understanding of the British education system, low expectations from teachers, lack of fluency in English and poverty and overcrowding (Sales et al., 2008; Tereshchenko and Archer, 2014; Strand et al., 2015; Demie, 2018a). Most parents do not understand the levels as a measure of a child's attainment, and many Eastern European families live in deprived neighbourhoods with overcrowded accommodation. Teachers also highlighted English language as the main barrier for Eastern European children. Parents who are unable to speak English themselves have also limited ability to help their children with work. In addition, other research also highlights that pupils taking free school meals (FSM), which is a proxy measure of poverty, perform less well generally than their non-FSM counterparts (Gorard and See, 2013). This is further supported by another recent report stating that 'poverty makes things harder ... Some $68 \%$ of Lithuanian-speaking children and $63 \%$ of Polish-speakers live in poor areas, where schools tend to be worse' (The Economist, 2017: 23). 
A recent review of literature also suggests that with the rapid rate of globalization there has been a dramatic increase in interest in the study of bilingualism (Conteh, 2012; Creese, 2011; Wallace, 2013), first language use when supporting early EAL children in the classroom (Evans et al., 2016) and translanguaging (Wei and Wu, 2009).

Overall, the literature review suggests that because of a lack of available data there is little research into the achievement of Eastern European pupils. There are no reliable statistics on the Eastern European population as a separate ethnic group in Britain, and there is little clarity on the number of Eastern European pupils in schools. Additionally, the educational underachievement of Eastern European students in British schools has seldom been mentioned in the standards debate in the last decade. Despite much academic debate, and policymakers' concern about underachievement in schools, the needs of Eastern European pupils have not been addressed and are overlooked by local and national policymakers because of the failure to recognize pupils from Eastern Europe as a distinct ethnic group in data collection.

The organization of this article is as follows. First, the research questions, data sources, terminology and measure of pupil performance used are described. Second, the linguistic diversity of Eastern Europeans in England is discussed to provide a context for subsequent analysis. Third, the attainment of Eastern European pupils by languages spoken is examined, followed by the factors affecting the achievement of Eastern European pupils in schools. The article concludes with the implications of the data for policymakers and practitioners in responding to the support needs of different Eastern European groups.

\section{Aims}

The aims of this research article are to explore the attainment of Eastern European children and to examine the reasons for underachievement in schools. It considers empirical evidence from England and examines pupil performance differences among main Eastern European languages spoken in schools in addition to English. Three overarching questions guided this research:

- What do the data tell us about language diversity and Eastern European pupils' attainment?

- What are the factors influencing performance of Eastern European pupils in English schools?

- What are the implications for policy and practice?

\section{Data and method}

To answer the questions, the research draws on detailed NPD and School Census data for pupils who completed KS2 in England in 2016. The NPD data used matched pupil information on ethnicity, language spoken at home, FSM, levels of fluency in English, and gender to pupil level attainment. The sample size of the pupils who completed KS2 at the end of Year 6 in 2016 was 586,181.

Two methodological approaches were used to analyse the data. First, performance of all pupils was analysed by ethnic and language background to illustrate patterns of attainment for each group. Second, attainment data were further analysed by social background factors to explore the main factors influencing performance in schools, and the reasons for underachievement. 


\section{Measures of pupil performance}

In the English education system, pupils aged 10 to 11 years at the end of Year 6 take the KS2 tests. These are a series of tests in reading, maths and writing (teacher assessment), and for the purposes of this article, performance is measured by the percentage of pupils reaching the expected standard in reading, writing and maths combined (expected levels). Underachievement is defined as attainment that is below the national average or below age-related expectations.

\section{Terminology}

The term 'Eastern Europe' is used here to refer to the eastern part of Europe that encompasses many different cultures, ethnicities, languages and histories. A review of literature suggests that grouping all of these countries under a single designation can sometimes be problematic. However, it is important to note that the countries broadly classified as being part of Eastern Europe share a common past - they were all behind the Iron Curtain before its fall in the 1990s. For the purposes of this research, we have defined Eastern European speakers as people who speak one of these languages: Albanian, Armenian, Bulgarian, Chechen, Czech, Estonian, Georgian, Hungarian, Latvian, Lithuanian, Macedonian, Moldovan, Polish, Romanian, Russian, Serbian, Croatian, Bosnian, Slovak, Slovenian and Ukrainian. For comparison, we have defined Western European speakers to have a White Other ethnic background, and to speak one of these languages: Basque/Euskara, Catalan, Danish, Dutch/Flemish, Finnish, French, German, Greek, Icelandic, Italian, Luxembourgish, Norwegian, Portuguese, Sardinian, Spanish and Swedish. Turkish and Kurdish language speakers are also added to the group on the grounds of geographical links.

\section{Language diversity and attainment of Eastern European pupils in primary schools in England}

Pupils speaking the languages of Eastern Europe as their mother tongue are the fastest-growing group in English schools, having increased by 135 per cent between 2008 and 2012 (see Tereshchenko and Archer, 2014). However, the literature review confirms that there is a lack of national comparative attainment data to identify patterns of achievement of children of Eastern European heritage in English schools.

Despite the prominence of this group in public policy, there is still no research evidence or national data of the educational achievement and experiences of schooling among Eastern European pupils in England. This places serious constraints on effectively targeting policy and practice developments at national and local level.

The analysis on performance by ethnic group as highlighted in the literature review is invaluable in improving our knowledge related to a pupils' background and achievement, but it is important to be cautious when using the national school census ethnic categories. Ethnic categories aggregate a wide range of nationalities, cultures and backgrounds. 'White Other' can include pupils from Western and Eastern Europe, as well as other parts of the world. There is also a tendency to group all African countries as one homogeneous mass, but Black African pupils can be from a wide range of countries that are very culturally and sociologically diverse, as well as being of British nationality with English being spoken as the first language. However, within each ethnicity, they will be a variety of languages spoken. We would argue that studying the languages spoken by pupils may provide greater insight into the broad categorization of ethnic banding, helping to examine attainment and identify underachieving groups. 


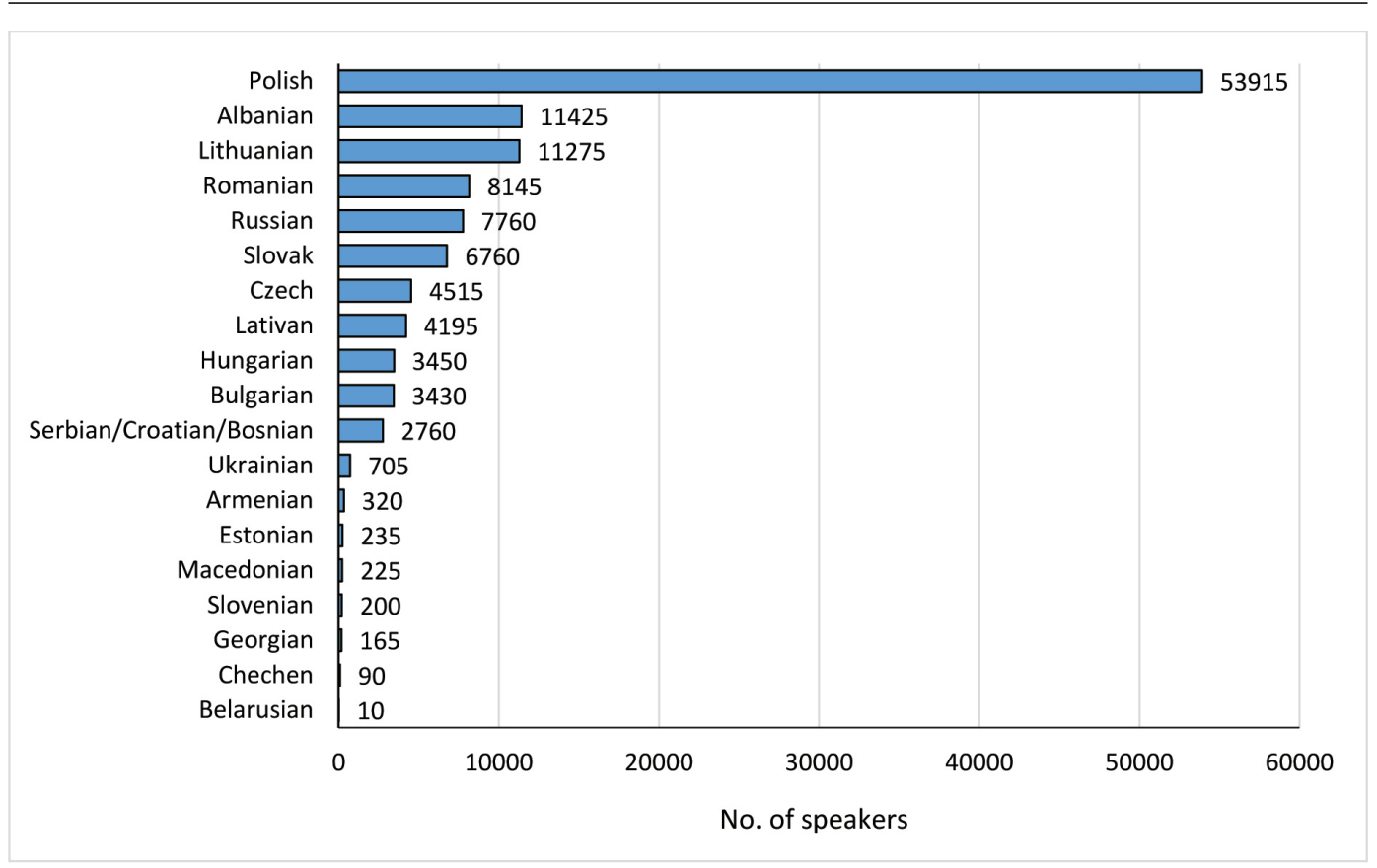

Figure 1: Eastern European languages spoken in English schools by number of speakers

Source: NALDIC (2015), 2012 data

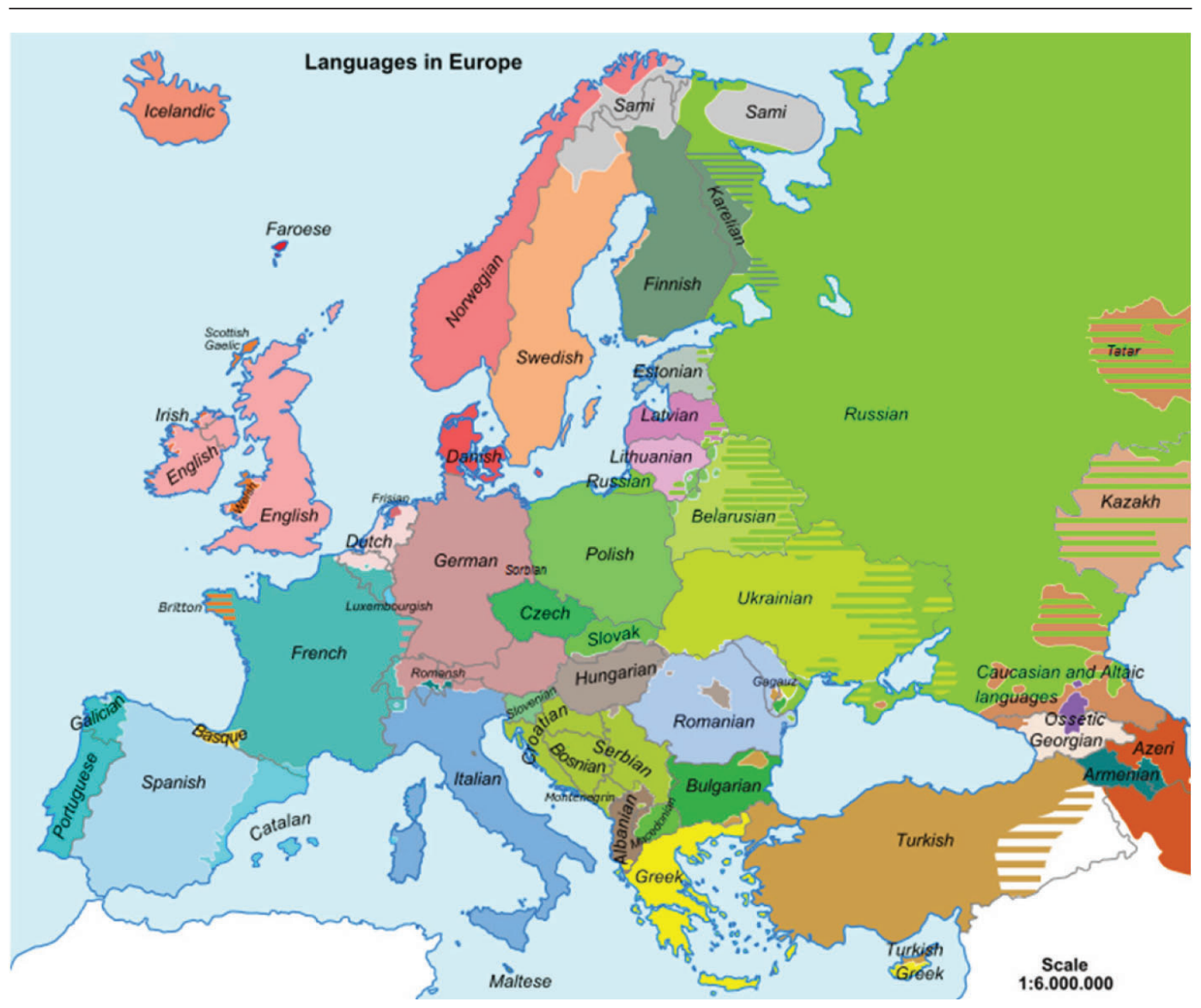

Figure 2: Map of languages in Europe

Source: https://en.wikipedia.org/wiki/Languages_of_the_European_Union\#/media/ File:Simplified_Languages_of_Europe_map.svg 
Table 1: Key Stage 2 attainment by Eastern European language (percentage reaching the expected level)

\begin{tabular}{|c|c|c|c|c|c|}
\hline First language & $\begin{array}{l}\text { Reading } \\
\text { KS2 (\%) }\end{array}$ & $\begin{array}{l}\text { Writing } \\
\text { TA }^{\star \star}(\%)\end{array}$ & $\begin{array}{c}\text { Maths } \\
\text { KS2 (\%) }\end{array}$ & $\begin{array}{l}\text { RWM }^{*} \\
(\%)\end{array}$ & $\begin{array}{l}\text { Number } \\
\text { of pupils }\end{array}$ \\
\hline Georgian & 73 & 82 & 91 & 68 & 22 \\
\hline Macedonian & 72 & 81 & 81 & 66 & 32 \\
\hline Moldovan & 73 & 86 & 82 & 64 & 22 \\
\hline Serbian-Croatian-Bosnian & 71 & 77 & 77 & 59 & 310 \\
\hline Ukrainian & 63 & 70 & 84 & 57 & 118 \\
\hline Slovenian & 59 & 75 & 72 & 56 & 32 \\
\hline Russian & 61 & 73 & 79 & 54 & 1,067 \\
\hline Albanian & 63 & 76 & 75 & 54 & 1,248 \\
\hline Estonian & 65 & 81 & 74 & 52 & 31 \\
\hline Armenian & 71 & 76 & 71 & 50 & 34 \\
\hline Chechen & 75 & 75 & 50 & 50 & 4 \\
\hline Bulgarian & 50 & 63 & 68 & 45 & 747 \\
\hline Polish & 52 & 66 & 71 & 44 & 7,687 \\
\hline Lithuanian & 46 & 65 & 67 & 39 & 1,504 \\
\hline Latvian & 48 & 63 & 64 & 38 & 641 \\
\hline Hungarian & 45 & 53 & 59 & 37 & 748 \\
\hline Romanian & 35 & 47 & 53 & 30 & 2,425 \\
\hline Czech & 26 & 39 & 35 & 19 & 631 \\
\hline Slovak & 22 & 32 & 30 & 18 & 1,037 \\
\hline All Eastern European & 48 & 61 & 65 & 41 & 18,340 \\
\hline National (all pupils) & 66 & 74 & 70 & 53 & \\
\hline Difference & -18 & -13 & -5 & -8 & \\
\hline $\begin{array}{l}\text { * RWM: Reading, writing anc } \\
\text { **TA: Teacher assessed } \\
\text { Source: DfE (2016a) }\end{array}$ & s com & & & & \\
\hline
\end{tabular}

Figures 1 and 2 show that Eastern Europe is one of the most linguistically diverse parts of the European continent, with 53,915 pupils speaking Polish as their language at home, followed by speakers of Albanian (11,425 speakers), Lithuanian (11,275), Romanian (8,145), Russian (7,760), Slovak $(6,760)$, Czech $(4,515)$, Latvian $(4,195)$, Hungarian (3,450), Bulgarian (3,450) and Serbian/Croatian/Bosnian (2,760). Other languages spoken include Ukrainian, Armenian, Estonian, Macedonian, Slovenian, Georgian, Chechen and Belarusian, which have between 700 and 10 speakers. Overall, more than 24 different languages were spoken at home by Eastern European pupils in the NPD.

Table 1 also shows that Eastern European pupils at KS2 are a linguistically diverse group, with Polish $(7,687)$ being the most commonly spoken language, closely followed by the large cohort of Lithuanian-speaking pupils $(1,504)$, Romanianspeaking pupils $(2,425)$ and Albanian-speaking pupils $(1,248)$. Also, sizable numbers of pupils speak Slovak, Russian, Hungarian, Bulgarian and Czech. In addition, there are pupils who speak Estonian, Ukrainian, Armenian, Macedonian, Serbian/Croatian/ Bosnian and Georgian. In total, 19 different Eastern European languages were spoken in primary schools in England. There were 1,340 pupils of Eastern European 
origins who took KS2 in 2016. In general, the number of speakers of Eastern European languages involved makes the analysis statistically valid, and allows for meaningful statistical comparison and interpretation. However, we need to be cautious in the interpretation for languages spoken by fewer than 20 pupils, as they may be considered too small for comparisons.

There is a clear difference in performance when the results are broken down by language spoken. Overall, 41 per cent gained the expected standard in reading, writing and maths combined, compared with 53 per cent of all pupils nationally. The biggest attainment gap was in reading, where 66 per cent of pupils nationally and 48 per cent of Eastern European language speakers met the expected standard.

There are wide variations in attainment for different language groups within Eastern Europe. Eastern European pupils overall are considered to be an underachieving group, but when this is disaggregated by languages spoken by the pupil, there are several language groups that are very high performing compared to the national average in England. Table 1 and Figure 3 show that within the Eastern European language groups, Georgian-speaking pupils were the highest achieving, with 68 per cent meeting expected levels. They were closely followed by the pupils speaking Macedonian (66 per cent), Romanian (64 per cent), Serbian/Croatian/Bosnian (61 per cent), Ukrainian (57 per cent), Slovenian (56 per cent), Russian and Albanian (both 54 per cent), who performed above the national average at KS2 (see Table 1). Notably, of the largest groups from Eastern Europe, Russian and Albanian speakers achieved better than the national average.

In contrast, Slovak-speaking pupils were by far the lowest-performing in the White Other category, with just 18 per cent of pupils achieving expected levels at KS2, followed by Czech-speaking pupils (19 per cent); they are among the lowestperforming language groups across the country, being over 44 percentage points below the national average. Also low-achieving from the Eastern European group were speakers of Romanian (30 per cent), Latvian (38 per cent), Hungarian (37 per cent), Lithuanian (39 per cent), Polish (44 per cent), Bulgarian (45 per cent) and Estonian (52 per cent). The underachievement of these Eastern European White Other language groups is corroborated by the findings of the analysis done on KS2 pupils in 2012 and 2014, which found all of these language groups underperforming and comparisons of level and attainment gap being remarkably congruous (Demie, 2018b).

Table 2: Key Stage 2 attainment by language area (percentage reaching the expected level)

\begin{tabular}{lccccc}
\hline & $\begin{array}{c}\text { Reading } \\
\text { KS2 (\%) }\end{array}$ & $\begin{array}{c}\text { Writing } \\
\text { TA** }(\%)\end{array}$ & $\begin{array}{c}\text { Maths KS2 } \\
(\%)\end{array}$ & $\begin{array}{c}\text { RWM }^{*} \\
(\%)\end{array}$ & $\begin{array}{c}\text { Number } \\
\text { of pupils }\end{array}$ \\
\hline $\begin{array}{l}\text { Eastern European language } \\
\text { speakers }\end{array}$ & 48 & 61 & 65 & 41 & 18,340 \\
$\begin{array}{l}\text { Western European language } \\
\text { speakers }\end{array}$ & 57 & 69 & 71 & 48 & 6,629 \\
$\begin{array}{l}\text { White British English } \\
\text { speakers }\end{array}$ & 68 & 74 & 69 & 54 & 404,146 \\
$\begin{array}{l}\text { White Irish English speakers } \\
\text { National }\end{array}$ & 77 & 78 & 75 & 61 & 1,670 \\
\hline
\end{tabular}

* RWM: Reading, writing and maths combined

**TA: Teacher assessed

Source: DfE (2016a) 
Overall, Eastern European language speakers of Czech, Slovak, Hungarian, Latvian, Romanian and Lithuanian make up some of the lowest-achieving groups of all the languages spoken. This is an area that requires further scrutiny. Czech and Slovak pupils in particular are very low-achieving, over 40 percentage points below the national average at KS2. Researchers have suggested that a large proportion of Czechand Slovak-speaking pupils in England may belong to the Roma migrant community (Tereshchenko and Archer, 2014), a disadvantaged group that is known to provide a low level of access to education for their children.

A further analysis of the attainment of Eastern European and Western European pupils suggests that Eastern European speakers do less well than Western European speakers at KS2, and that White British English-only speakers do better by a clear margin (see Table 2). However, it is the White Irish English speakers who have the highest levels of attainment, with 61 per cent gaining the expected standard in reading, writing and maths combined. The underachievement of Eastern European language speakers is certainly worthy of more detailed investigation.

\section{Eastern European pupils attainment at KS2 by region in England}

There is also a wide variation in performance between regions in England, with large attainment gaps between Eastern European children and White British children.

Table 3: KS2 performance of Eastern European pupils by regions in England (percentage reaching the expected level)

\begin{tabular}{|c|c|c|c|c|c|c|c|}
\hline \multirow[b]{2}{*}{ Region } & \multicolumn{4}{|c|}{$\begin{array}{l}\text { Different language speakers by } \\
\text { regions in England (\%) }\end{array}$} & \multicolumn{3}{|c|}{$\begin{array}{c}\text { Eastern European and } \\
\text { White British Attainment } \\
\text { Gap -RWM* }(\%)\end{array}$} \\
\hline & Other** & $\begin{array}{l}\text { Eastern } \\
\text { European }\end{array}$ & $\begin{array}{l}\text { White } \\
\text { British }\end{array}$ & $\begin{array}{c}\text { All } \\
\text { Pupils }\end{array}$ & $\begin{array}{l}\text { Eastern } \\
\text { European }\end{array}$ & $\begin{array}{l}\text { White } \\
\text { British }\end{array}$ & Gap \\
\hline East Midlands & 19 & 3 & 77 & 50,256 & 33 & 52 & -19 \\
\hline East of England & 21 & 4 & 75 & 64,987 & 39 & 53 & -14 \\
\hline Inner London & 78 & 6 & 16 & 31,346 & 57 & 67 & -10 \\
\hline North-East & 9 & 1 & 90 & 27,972 & 34 & 57 & -23 \\
\hline North-West & 21 & 2 & 78 & 80,990 & 32 & 54 & -22 \\
\hline Outer London & 62 & 7 & 31 & 58,769 & 49 & 60 & -11 \\
\hline South-East & 21 & 3 & 77 & 91,317 & 44 & 55 & -11 \\
\hline South-West & 12 & 2 & 86 & 54,504 & 40 & 53 & -13 \\
\hline West Midlands & 32 & 2 & 65 & 66,016 & 32 & 52 & -20 \\
\hline Yorkshire and Humber & 22 & 3 & 75 & 60,024 & 26 & 51 & -25 \\
\hline England & 28 & 3 & 69 & 586,181 & 41 & 54 & -13 \\
\hline
\end{tabular}

* RWM: Reading, writing and maths combined

** 'Other' languages includes Western European and other language speakers in schools in England from different parts of the world

Source: DfE (2016a)

Table 3 shows a breakdown of attainment of Eastern European language speakers by regions in England at the end of primary education. The key findings here suggest that pupils in outer London are most likely to speak Eastern European languages (6.9 per cent), followed by inner London (5.9 per cent), while pupils in the North-West and North-East were the least likely, at 1.5 per cent and 1.2 per cent respectively. The data 
also show that there was a much higher rate of Western Europeans in inner London than anywhere else in the country by a clear margin, with 12.3 per cent of all pupils speaking a Western European language, twice the rate of outer London, while the incidence in the rest of the country ranges from 1 to 2 per cent.

Using the empirical data from the 2016 NPD, the achievement of KS2 Eastern European pupils was examined by the region of England in which they live (see Table 3). There is a wide variation in performance between regions in England, with large attainment gaps between Eastern European children and White British children. The NPD data show that Eastern European pupils in inner and outer London perform better than pupils in all other parts of the country, with 57 per cent and 60 per cent achieving expected levels or better respectively (see Table 3). Eastern European pupils from all other regions were performing well below the national average at KS2. Inner London, outer London and, to a lesser extent, the South-East, appear to show higher attainment for their Eastern European learners, where the gaps in attainment between Eastern European and White British are much narrower. In contrast, EAL pupils in Yorkshire and the Humber especially, but also regions such as the east of England, East and West Midlands and the South-West have low achievement with wider gaps. The North-West and, in particular, the North-East are highlighted as regions with an underachieving Eastern European cohort, while their White British peers are achieving above the national average. Overall, Eastern European pupils living in Yorkshire and the Humber were the lowest-achieving, with only 26 per cent achieving the expected standard. Yorkshire and the Humber also showed the biggest gap in achievement between Eastern European and White British.

\section{Factors affecting the achievement of Eastern European pupils in schools}

There is much research into factors affecting performance in schools. Recent British studies have focused on the relationship between educational achievement and factors such as gender, ethnicity, pupil mobility and FSM, but the literature review suggests there has been little research into factors affecting the performance of Eastern European pupils. Previous studies (Demie, 2015; Sales et al., 2008) attribute the roots of Eastern European pupil underachievement to a number of factors, including poverty, lack of understanding of the British education system, lack of fluency in English and overcrowding. There is evidence that many Eastern European families live in deprived neighbourhoods with overcrowded accommodation. There is also evidence of racism during the Brexit debate; despite claims of diversity and racial equality in the media and among educational professionals, teachers are a part of a wider community, which, like every community, has cultural prejudices (Sales et al., 2008; Tereshchenko and Archer, 2014). In this research, three factors that are measurable and helpful in understanding the effect of background factors on attainment of Eastern European pupils in schools were considered - eligibility for FSM, pupil mobility and levels of fluency in English. The findings from the NPD data confirm that Eastern European pupils are somewhat less disadvantaged. For example, Eastern European language speakers were about half as likely to be eligible for FSM as pupils in England overall (8.7 per cent versus 15.5 per cent nationally). In addition, the incidence of statemented pupils was notably lower, at 1.7 per cent compared with 3 per cent nationally. Similarly, 12.6 per cent of Western European language speakers were also less likely to be eligible for FSM, and 1.9 per cent of pupils were statemented (DfE, 2016a). 


\section{Disadvantage and attainment of Eastern European pupils}

One key factor affecting achievement of Eastern European pupils in English schools is the poverty associated with socio-economic status. The FSM variable is often used as a proxy measure of the extent of social deprivation in the background of pupils, and has been linked to underachievement in a number of studies (Demie, 2018a; DfE, 2016a; Gorard and See, 2013). Several studies confirm that that there are long-standing achievement gaps in England associated with socio-economic status (Cassen and Kingdon, 2007). Research by the Joseph Rowntree Foundation also suggested that there will be 3.5 million children in the UK living in poverty by 2020, many in households where there has been no experience of work (Maclnnes et al., 2014). Gorard and See's (2013) research also suggests that children start school with different levels of resources, and begin to display strong patterning by family origin in their school attainment. This pattern continues at every subsequent age and stage throughout children's schooling. Certainly, aggregate scores and qualifications for students from those living in poverty are considered lower than average, despite a system set up purportedly to prevent this (Gorard and See, 2013). Of particular concern is that children from poorer homes do worse educationally than their classmates. Overall in England, the gap in attainment between those eligible for FSM and those who paid for a meal was 20 percentage points (35 per cent and 55 per cent respectively). There remains a significant gap between FSM pupils and non-FSM pupils (see Table 4). Despite this national evidence, Eastern European pupils experience relatively low level of disadvantage relative to national norms. The proportion of pupils taking KS2 in 2016 eligible for FSM was 9 per cent, compared to 16 per cent of pupils nationally.

Table 4: Differences in attainment at KS2 for Eastern European pupils by FSM and mobility rate (reading, writing and maths combined)

\begin{tabular}{|c|c|c|c|c|c|c|c|c|}
\hline & \multicolumn{2}{|c|}{ Non-FSM } & \multicolumn{2}{|c|}{ FSM } & \multicolumn{2}{|c|}{ Non-mobile } & \multicolumn{2}{|c|}{ Mobile } \\
\hline & $\%$ & Pupils & $\%$ & Pupils & $\%$ & Pupils & $\%$ & Pupils \\
\hline $\begin{array}{l}\text { Eastern European } \\
\text { languages }\end{array}$ & 42 & 14,277 & 33 & 1,592 & 51 & 12,547 & 19 & 5,793 \\
\hline $\begin{array}{l}\text { Western European } \\
\text { languages }\end{array}$ & 50 & 8,888 & 39 & 2,691 & 53 & 10,750 & 28 & 3,867 \\
\hline $\begin{array}{l}\text { White British } \\
\text { English speakers }\end{array}$ & 61 & 287,883 & 32 & 58,193 & 54 & 398,229 & 50 & 5,917 \\
\hline \multirow[t]{2}{*}{$\begin{array}{l}\text { White Irish } \\
\text { English speakers }\end{array}$} & 70 & 2 & 37 & 272 & 63 & 1,490 & 51 & 180 \\
\hline & 55 & 493,559 & 35 & 91,129 & 54 & 557,590 & 34 & 28,591 \\
\hline
\end{tabular}

Source: DfE (2016a)

Table 4 indicates that there is a marked difference in KS2 performance between pupils eligible for FSM and the most economically advantaged groups in schools at the end of primary education. The gap was much smaller for both those speaking Eastern European and Western European languages, at 8 percentage points and 9 percentage points. For these groups of pupils, those eligible for FSM had similar levels of performance as found nationally, but for those who paid for a meal, their attainment was much lower than that found in England overall. 
When broken down into the individual languages, a varied picture emerges. Of Albanian speakers, 30 per cent were eligible for FSM, the highest proportion of any group, but those pupils also were more likely to meet the expected standard in reading, writing and maths than were pupils speaking any other language, with 50 per cent achieving this. For Albanian speakers, there was a gap of just 6 percentage points between those eligible and those not eligible - the smallest gap recorded.

Overall, the findings from the national data demonstrate that attainment of Eastern European pupils eligible for FSM mirrors that found nationally, but more affluent Eastern European pupils are much less likely to attain at the same standard as in England overall. This does not follow the same pattern found by White British pupils, where there is a more pronounced gap.

\section{Pupil mobility and attainment of Eastern European pupils}

Another important factor that affects Eastern European pupils' performance is pupil mobility. Mobile pupils are those who join or leave school at a point other than at the age they would normally start or finish their education at school. In the past few years, there has been increasing concern about pupil mobility in schools. Previous research in this area has generally focused on establishing the extent of pupil mobility problems in schools (Strand and Demie, 2007; Dobson and Heathorne, 1999). It is now widely recognized that mobility can have an adverse effect on educational attainment. For example, the findings from early work by Strand and Demie (2007) indicate that there is high mobility in London schools. Demie et al.'s (2005) study further confirmed that nearly half of children in their sample of KS2 primary schools had attended at least one other school and that there is high mobility in some schools. The national survey by Dobson and Heathorne (1999), which investigated the pattern of inward and outward mobility, also reported an average mobility level of 10-20 per cent across all primary schools and 8-12 per cent in secondary schools. Research by Demie et al. (2005) also suggested that the vast majority (92 per cent) of head teachers who responded to the survey thought that it was either very or fairly important for schools to address mobility issues and that mobile pupils were underachieving in English schools. The overwhelming message from these research findings is that pupil mobility is a common experience in schools. Overall, the main findings suggest that high mobility has been found to affect academic performance at all levels. Pupils who have had many terms in the same school tend to achieve better results than those who have to change schools frequently. However, there has been little research as yet into the relationship between mobility factors and achievement in school for Eastern European pupils.

Table 4 shows the comparative performance of mobile and non-mobile, or 'stable', pupils within the local education authority. For the purposes of this research, the term 'mobile pupils' refers to pupils who first joined the English school system in Year 3 or later. There is a striking gap in attainment between mobile and non-mobile pupils: 19 per cent of Eastern European pupils who were mobile reached the expected standard in reading, writing and maths combined, but 51 per cent of stable pupils met this standard. The position was similar between the two groups when one looks at the difference in performance in reading, writing and maths. The biggest difference at KS2 between the two groups was in reading, writing and maths, with a gap of 32 percentage points in favour of non-mobile pupils. It is likely that the majority of mobile Eastern European pupils have less than four years' schooling in the English education system. 
Without question, pupil mobility is a major factor affecting the performance of Eastern European pupils in schools. A comment from a primary head teacher captures the climate and the views in the schools about pupil mobility, which supports some of the conclusions and policy implications raised in this article:

Mobility is an issue in my school and affects the school performance ... We need extra financial resources to identify and appropriately target those children who need more induction and to allocate a dedicated teacher/ teacher assistant to provide more intensive support. (Primary headteacher, Demie et al., 2005: 5)

\section{EAL stages of English proficiency and attainment of Eastern European pupils}

A major factor that affects the attainment of Eastern European EAL pupils is lack of English fluency. For pupils to have access to the curriculum, it is clear that they need to be fluent in the language of instruction. Research on the relationship between fluency in English and attainment in inner London also confirms that lack of fluency in English remains one of the key factors affecting the performance of Eastern European pupils in British schools (Demie, 2018a). There are no national validated scales that are complementary to the current English assessment scales used in the national curriculum (Demie, 2015). However, this study, based on well-moderated English fluency stages at local authority level by EAL professionals, teachers and local authority advisers (see Strand and Demie, 2005; Demie, 2013, 2018a), confirmed that there is a strong relationship between stage of fluency in English and educational attainment. The results suggest that the percentage of pupils meeting national standards at KS2 and GCSE increased as stage of proficiency in English increased. Pupils in the early stages of fluency performed at low levels, while Eastern European pupils who were fully fluent in English far outstripped pupils for whom English was their only language (Demie, 2013; Strand and Demie, 2005).

However, proficiency data for Eastern European pupils is not available at the national level. The government has started collecting EAL proficiency data, but this data is not yet available. As a result of a lack of national data, we will use data from an inner London local authority as a case study. The EAL learning needs of pupils vary greatly from beginners to advanced learners. The five stages of national English proficiency are used in the local authority's schools as a diagnostic tool to analyse needs for future teaching focus, and to provide baseline information for statistical purposes.

Table 5 gives the average performance of Eastern European pupils at the end of primary school in the local authority. The results of the KS2 tests analysis in 2017 show that pupils with EAL at the early stages of developing fluency in English had significantly lower KS2 test scores than their monolingual peers. The percentage of pupils achieving expected levels increased as the stage of proficiency in English increased. Eastern European pupils with EAL who were fully fluent in English achieved significantly higher scores at KS2 (94 per cent) and were more likely to achieve the expected standard than even monolingual English-only speakers (71 per cent). Only 48 per cent of EAL pupils who were not fluent in English (Stages A to D) achieved expected levels at KS2, suggesting this group to be one of the more underachieving in the UK. 
Table 5: KS2 results in reading, writing and maths combined (RWM) by stage of fluency in English, 2017

\begin{tabular}{|c|c|c|c|c|}
\hline \multirow{2}{*}{ EAL proficiency stage } & \multicolumn{2}{|c|}{$\begin{array}{l}\text { Local authority } \\
\text { (all pupils)* }\end{array}$} & \multicolumn{2}{|c|}{$\begin{array}{c}\text { Eastern European } \\
\text { pupils** }\end{array}$} \\
\hline & $\begin{array}{l}\% \mathrm{KS2} \\
\text { pupils }\end{array}$ & $\begin{array}{l}\% \mathrm{KS2} \\
\text { RWM }\end{array}$ & $\begin{array}{l}\% \mathrm{KS2} \\
\text { pupils }\end{array}$ & $\begin{array}{l}\% \text { KS2 } \\
\text { RWM }\end{array}$ \\
\hline Stage A (New to English) & 1.1 & 0 & 2.9 & 0 \\
\hline Stage B (Early acquisition) & 3.3 & 12.2 & 13.0 & 11.1 \\
\hline Stage C (Developing competence) & 13.2 & 55.8 & 26.1 & 38.9 \\
\hline Stage D (Competent) & 16.3 & 67.3 & 23.2 & 84.4 \\
\hline Stage E (Fluent) & 16.9 & 85.8 & 33.3 & 93.5 \\
\hline Not fluent (A-D) & 35.0 & 56.4 & 65.2 & 47.8 \\
\hline All EAL (A-E) & 51.9 & 66.0 & 98.6 & 63.2 \\
\hline Monolingual English speakers only & 46.7 & 71.4 & 0 & 0 \\
\hline All KS2 pupils & 100.0 & 68.7 & 100.0 & 63.2 \\
\hline \multicolumn{5}{|c|}{$\begin{array}{l}\text { *The number of 'all' local authority pupils at the end of KS2 is 2,957 } \\
\text { **The number of Eastern European pupils at the end of KS2 is } 138 \\
\text { Source: Schools Research and Statistics Unit, case study inner London local authority }\end{array}$} \\
\hline
\end{tabular}

In the few studies where language differences and educational achievement are considered, the importance of language spoken at home and English language fluency in achievement is very rarely examined, due to the constraint of the categorization used in official statistics, and particularly due to the lack of national data about fluency in English.

There were 138 Eastern European pupils taking KS2 in the case study local authority, including Polish, Albanian, Bulgarian, Romanian and Slovak, Lithuanian and Serbo-Croatian language speakers. About 63 per cent of Eastern European pupils were not fluent in English. What is also evident from the local authority data is that none of the pupils who were on Stage A (New to English) and Stage B (Early acquisition) achieved the expected standards at KS2. The language groups that demonstrate low levels of attainment suggest that they are more likely to include pupils who are new to the country or have only recently settled in the UK.

However, Eastern European pupils who were fully fluent in English substantially outperformed those who were not fluent in English. This pattern is repeated across nearly all language groups. This is consistent with the previous findings, and again encouragingly confirms that once the barrier of language is overcome, it is possible for all pupils to achieve well. More importantly, we would argue that these groups of pupils are more likely to have lived and settled in the country long enough to acquire full fluency in English, or were born here.

There is consensus now from the literature reviews that Eastern European learners need to gain English proficiency quickly in order to do well in school. There is also solid evidence that most Eastern European learners who are in the English school system eventually become proficient in English (see Strand and Demie, 2005; Demie, 2015). 


\section{Conclusions and implications for policy and practice}

\section{Conclusions}

This research aims to examine Eastern European children's attainment to improve our knowledge about pupils at the end of primary school in England. The findings of the analysis of 586,181 pupils' KS2 results by language spoken at home suggest that, overall, pupils who speak an Eastern European language do less well than other groups and that their low attainment is a key concern for policymakers and teachers. However, while this is true overall, there were wide differences in performance when broken down by individual language. Within the Eastern European groups, there is a large variation in performance depending on the language that is spoken. The empirical data suggest that, in particular, speakers of Czech, Slovak, Hungarian, Polish, Russian, Italian, Romanian, Latvian, Lithuanian, Albanian and Bulgarian are underachieving, and that the difference between their educational performance and that of others is larger than for any other main groups. In contrast, speakers of West European languages such as French, Danish, Swedish, Dutch and German achieve better than the national average. Very few Czech- and Slovak-speaking pupils achieved expected outcomes. Of the larger European language groups in English schools, Polish speakers were achieving below the national average.

There is also wide variation in performance between regions in England, with large attainment gaps between Eastern European children and White British children. There are a number of reasons for underachievement in schools. An important key factor identified as the main reason for underachievement is the lack of English fluency. An examination of the effect of level of fluency in English on pupil performance confirms that there is a strong relationship between the stage of fluency in English and educational attainment. The results suggest that the percentage of pupils attaining the expected standard at KS2 increased as stage of proficiency in English increased. Eastern European pupils in the early stages of fluency performed at low levels, while EAL pupils who were fully fluent in English far outstripped those of pupils for whom English was their only language. Overall, the conclusion from this study suggests that lack of fluency in English remains the key factor affecting the performance of EAL pupils in English schools.

Another key factor affecting the achievement of Eastern European pupils in English schools is the poverty associated with socio-economic status. The NPD data indicate that there is a marked difference in KS2 performance between pupils eligible for FSM and the most economically advantaged groups in schools at the end of primary education. The gap was much smaller for both those speaking Eastern European and West European languages, at 8 percentage points and 9 percentage points. For these groups of pupils, those eligible for FSM had similar levels of performance to those found nationally, but for those who paid for a meal, their attainment was much lower than that found in England overall. Overall, the findings from the national data confirm that Eastern European pupils eligible for FSM perform considerably less well than their more affluent peers.

Pupil mobility also affects Eastern European pupils' performance. The main findings from the data indicate that those Eastern European pupils who joined an English school after KS1 recorded a striking attainment gap of 32 per cent at KS2 compared to other pupils. About 51 per cent of 11 -year-old stable pupils achieved the expected standard compared to 19 per cent of the mobile group. 
The overall conclusion from the study is that Eastern European pupils lag behind the average for England, and that England needs to improve the school performance of its biggest migrant group.

\section{Implications for data collection}

One of the contributions made by this article is to provide statistical evidence on languages used by Eastern European pupils, using data sets that have not previously been analysed, including the NPD in England and the English language proficiency census in one inner London local authority. This article also explores how the available language data in NPD may be used for analyses to examine the attainment of Eastern European children. The intention is to look at the possibility of extending the research to other language groups in schools in England. The evidence from the data confirms that pupils speaking the languages of Eastern Europe are one of the fastest-growing groups still underachieving in English schools. The overall findings of this study suggest that the underachievement of Eastern European children remains a cause for concern, and it is obviously an issue that policymakers and schools need to address. This research also shows how attainment data by language spoken at home is useful in tackling the underachievement of Eastern European pupils.

These findings also have implications for the collection and use of data at national and international level. We would argue that the worryingly low achievement of Eastern European pupils has been masked by the failure of government statistics to distinguish within the category 'White Other' ethnic group that is used in national data collection by languages spoken at home. Using such undifferentiated categories for data collected at national level in England can have undesirable consequences for policy formulation. Research shows that collapsing heterogeneous groups into the 'White Other' ethnic category makes comparison problematic, as this group had the greatest linguistic diversity, including a range of other ethnic groups such as Polish, Czech, Portuguese, Spanish, Albanian and Russian. We pointed out that accurate and reliable disaggregated ethnic and language data are important to address education inequalities. Such data are important to identify knowledge gaps and develop effective programmes and policies. We would argue that, as a matter of good practice, government and public institutions need an account of people's culture, ethnic and linguistic background in formulating national and local policy.

In light of our research, we have several suggestions for policy approaches to monitor performance and to tackle underachievement of Eastern European pupils in schools in England:

- We need to recognize the importance of cultural, ethnic and linguistic diversity in multicultural schools, and to value the contribution of the immigrant community to British society.

- Data on language spoken at home need to be collected to monitor performance of all groups to identify groups that are underachieving in schools.

- Teaching and learning in multicultural classrooms needs to be informed by highquality assessment and ethnic, linguistic and social background data.

\section{Implications for policy}

We argue that there are overall resourcing implications for national policymakers to address the underachievement of Eastern European pupils in English schools. The challenge from this research for national policymakers is that the government needs 
to recognize that the underachievement of Eastern European pupils is an important part of raising standards in schools. To tackle underachievement, central government and schools need to develop targeted initiatives to identify and address the needs of pupils of ethnic minorities. In the past, the Ethnic Minority Achievement Grant (EMAG) and ESOL (English for speakers of other languages) funding was introduced by the government as a means of supporting attainment of pupils from ethnic minority groups. The EMAG funding was designed to provide greater resources for schools with a higher proportion of ethnic minorities pupils, including Eastern Europeans. This has been the case for many years, but it was cut by the government from 2011 onwards. Similarly, huge cuts were imposed on ESOL budgets in England. There is now a need to review the national funding formula to support ethnic minority pupils to address the underachievement issues raised in this article.

\section{Implications for future research}

A research approach such as this that focuses on policy and practice is bound to have its critics, as it will not meet academic ideals of conventional research methodology of using a mixed quantitative/qualitative approach. Our research evidence is based on the data that is available at national level, and has not included any qualitative evidence that may give better insight into why some of the Eastern European pupils underachieve and what can be done to improve this. There is, therefore, a need for further research using mixed methods to get a fuller picture of the attainment of Eastern European pupils, including the reasons for underachievement. We argue that the study of the educational achievement of Eastern European pupils in schools, and its implications for performance, is a relatively under-researched field in England, but one of crucial importance to all involved in education. While this study represents a beginning for the study of Eastern European pupils' achievement in schools, it is our hope that it is a springboard for further research. We argue that this study identifies some limitations, with several possible avenues and questions for future research, including:

- What are the challenges of learning English in addition to their mother tongue for Eastern European pupils?

- What are the impacts of Standard English on the educational attainment of working-class children across ethnic boundaries?

- What can be done to improve bilingual children's learning using both mother tongue and English in the classroom?

- What does quantitative and focus group evidence tell us about the reasons for low attainment?

Despite these limitations, results from the present study do offer significant new insight, and extend our existing knowledge in the area of attainment for Eastern European pupils that can be used by policymakers, head teachers and teachers in the classroom. It provides data that have never been published before about ethnic and language background. The present findings also add to the body of research and wealth of empirical data relating to EAL pupils' levels of proficiency in English and attainment that may be used as a baseline for subsequent studies. Based on the findings of this study, we argue that there is a need to develop a national policy for raising achievement that better meets the needs of Eastern European learners in English schools. 


\section{Notes on the contributor}

Feyisa Demie is Honorary Fellow at Durham University School of Education and Head of Research and adviser for school self-evaluation at the London Borough of Lambeth.

\section{References}

Cassen, R. and Kingdon, G. (2007) Tackling Low Educational Achievement. York: Joseph Rowntree Foundation.

Conteh, J. (2012) 'Families, pupils and teachers learning together in a multilingual British city'. Journal of Multilingual and Multicultural Development, 33 (1), 101-16.

Creese, A. (2011) 'Pedagogy and bilingual pupils in primary schools: Certainties from applied linguistics'. In Ellis, S. and McCartney, E. (eds) Applied Linguistics and Primary School Teaching. Cambridge: Cambridge University Press, 186-98.

Demie, F. (2013) 'English as an additional language pupils: How long does it take to acquire English fluency?'. Language and Education, 27 (1), 59-69.

Demie, F. (2015) 'Language diversity and attainment in schools: Implication for policy and practice'. Race Ethnicity and Education, 18 (5), 723-37.

Demie, F. (2018a) 'English as an additional language and attainment in primary schools in England'. Journal of Multilingual and Multicultural Development, 39 (3), 210-23.

Demie, F. (2018b) 'English language proficiency and attainment of EAL (English as second language) pupils in England'. Journal of Multilingual and Multicultural Development, 39 (7), 641-53.

Demie, F., Lewis, K. and Taplin, A. (2005) 'Pupil mobility in schools and implications for raising achievement'. Educational Studies, 31 (2), 131-47.

DfE (Department for Education) (2016a) National Pupil Database (NPD). London: Department for Education.

DfE (Department for Education) (2016b) National curriculum assessments: Key Stage 2, 2015 (revised): National tables: SFR47/2015 - Summary. Online. http://tinyurl.com/p5vl3uz (accessed 3 April 2019).

DfE (Department for Education) (2017) School census 2016 to 2017: Guide for schools and LAs. Online. http://tinyurl.com/j8xp3fl (accessed 3 April 2019).

Dobson, J. and Henthorne, K. (1999) Pupil Mobility in Schools (DfEE Research Report RR168). Nottingham: Department for Education and Employment.

Dustmann, C., Machin, S. and Schönberg, U. (2010) 'Ethnicity and educational achievement in compulsory schooling'. Economic Journal, 120 (546), F272-F297.

Eurostat (2015) Key Figures on Europe. Luxembourg: Publications Office of the European Union. Online. http://tinyurl.com/y62avjjq (accessed 3 April 2019).

Evans, M., Schneider, C., Arnot, M., Fisher, L., Forbes, K., Hu, M. and Liu, Y. (2016) Language Development and School Achievement: Opportunities and challenges in the education of EAL students: Executive summary. Cambridge: Bell Foundation.

Gorard, S. and See, B.H. (2013) Overcoming Disadvantage in Education. London: Routledge.

Hollingworth, S. and Mansaray, A. (2012) Language Diversity and Attainment in English Secondary Schools: A scoping study. London: Institute for Policy Studies in Education.

Levy, A. (2014) 'English is now second language in one in nine schools after influx of Eastern Europeans'. Daily Mail, 21 February. Online. www.dailymail.co.uk/news/article-2565165/Englishsecond-language-one-nine-schools-influx-Eastern-Europeans.html (accessed 2 May 2019).

Maclnnes, T., Aldridge, H., Bushe, S., Tinson, A. and Born, T.B. (2014) Monitoring Poverty and Social Exclusion 2014. York: Joseph Rowntree Foundation. Online.

NALDIC (National Association for Language Development in the Curriculum) (2015) 'Languages in schools: More about the languages of bilingual pupils'. Online. www.naldic.org.uk/research-andinformation/eal-statistics/lang/ (accessed 13 May 2019).

ONS (Office for National Statistics) (2017) 'Living abroad: Migration between Britain and the EU8'. Online. http://tinyurl.com/y6sg93ro (accessed 3 April 2019).

Sales, R., Ryan, L., Lopez Rodriguez, M. and D'Angelo, A. (2008) Polish Pupils in London Schools: Opportunities and challenges. London: Multiverse and Middlesex University.

Slack, J. (2007) 'Schools are stretched to breaking point by immigrant children'. Daily Mail, 31 May. Online. www.dailymail.co.uk/news/article-458825/Schools-stretched-breaking-pointimmigrant-children.html (accessed 2 May 2019). 
Strand, S. and Demie, F (2005) 'English language acquisition and educational attainment at the end of primary school'. Educational Studies, 31 (3), 275-91.

Strand, S. and Demie, F. (2007) 'Pupil mobility, attainment and progress in secondary school'. Educational Studies, 33 (3), 313-31.

Strand, S., Malmberg, L. and Hall, J. (2015) English as an Additional Language (EAL) and Educational Achievement in England: An analysis of the National Pupil Database. London: Education Endowment Foundation. Online. http://tinyurl.com/yyyffkhc (accessed 3 April 2019).

Tereshchenko, A. and Archer, L. (2014) New Migration, New Challenges: Eastern European migrant pupils in English schools. London: King's College London.

The Economist (2017) 'New kids on the block'. The Economist, 424 (9049), 23.

Wallace, C. (2013) Literacy and the Bilingual Learner: Texts and practices in London schools. Basingstoke: Palgrave Macmillan.

Wei, L. and Wu, C.-J. (2009) 'Polite Chinese children revisited: Creativity and the use of codeswitching in the Chinese complementary school classroom'. International Journal of Bilingual Education and Bilingualism, 12 (2), 193-211. 